\title{
Linking Farmers to Markets: The Case of Zero Star Uni Pessoal*
}

\author{
V.P. Correia and M.F. Rola-Rubzen \\ Curtin University of Technology \\ Perth \\ Western Australia
}

Keywords: horticulture, East Timor, value chain, partnerships

\begin{abstract}
This paper presents a case study of how linkages between horticulture farmers and markets are being developed in Timor Leste, focussing on the case of Zero Star Uni Pessoal. As an approach to poverty alleviation, an international aid agency initiated a private sector development program. Apart from helping farmers increase agricultural production, private sector involvement was encouraged. By strengthening the linkages between Zero Star and farmers, farmers benefited in terms of increasing incomes. Buyers also benefitted in terms of improvements in quantity and quality of the product, and therefore higher returns from trading.
\end{abstract}

\section{INTRODUCTION}

It is well known that commercialization of small-scale, resource poor farmers can lead to higher productivity, greater specialization and higher incomes (Bernard and Spielman 2009). These, in turn, can lead to improvements in household food security, poverty reduction, agricultural development and economy-wide growth (Timmer 1997). However, with imperfect markets and high transaction costs, many small-scale farmers are unable to exploit the advantages from commercialization (de-Janvry et al.1991; Goetz 1992; Key et al.2000; Jayne et al.2006).

Linking farmers to markets is one of the approaches to help small-scale farmers participate effectively in the market place and assist poor producers increase their output. Improved marketing will likely contribute to increasing farmers' income and reducing poverty particularly in rural areas. As pointed by IFAD (2003), improved market access is of crucial and immediate importance to small-scale famers and rural poor households. It is also evident that they are important for enhancing agricultural-based economic growth and increasing rural incomes.

According to Shepherd (2006), farmers need to be linked to markets firstly, because the production push focus alone is no longer viable; secondly, ad hoc sales of small surpluses are not a realistic long-term approach and farmers need to respond to market demand. In this context, what farmers produce needs to be based on what the market demands. As stated by Shepherd (2007), there is now an increasing understanding that production support activities must be linked to market demand. Long term business partnerships also offer the greatest scope for increasing earnings. For instance, a case study of vegetable farmers from Madagascar showed that given the right incentives and contracting systems, small farmers can participate successfully in emerging value chains (Bernard and Spielman 2009). The same study argued that thousands of small farmers benefited because of a combination of effects such as improved access to inputs, credit, extension services, technology adoption, as well as from productivity spillover effects on other crops and enhanced income stability. 
In Timor Leste, improving agricultural productivity and farmer incomes has been a major focus of the government. Timor Leste is a newly independent country with agriculture as the main source of income for 80 per cent of its population. Agriculture production is, however, dominated by low input, low output subsistence farming. As a result, productivity and product quality are very low. These factors contribute to the low income of small-scale farmers. A variety of vegetables and spices are grown for home consumption and for income generation but the transportation network, roads and bridges, market infrastructure, poor extension systems and poor linkages between producers and buyers limit market access for perishable commodities.

Recognising the importance of the private sector in the economic development of East Timor, an international aid project supported the development of market linkages for vegetable farmers. The objective of this paper is to present the model of linking farmers to markets used in this initiative and to present its impact. Drawing from the lessons learned in the study, strategies to improve market linkages in Timor Leste are identified.

\section{RESEARCH APPROACH}

This study was conducted in Aileu, Maubisse, Hatubuilico and Dili, Timor Leste. The map of the study site is shown in Figure 1. Data gathered included primary and secondary data, and the data collection methods included face-to-face interviews, rapid rural appraisals and desk top research of current and related literature in linking farmers to markets. The approach used in this study is the case study method which is widely used in marketing and is well suited to the study of a phenomenon and dynamic and evolving markets (Westgren and Zering 1998; Alfaro and Rabade 2009). Case studies may focus on an individual, a group, or an entire community and may utilize a number of data gathering techniques such as documents, oral histories, in-depth interviews and participant observation (Hagan 2002 and Yin 1994). The case study presented in this paper is part of a larger study on linking farmers to markets in East Timor, currently being conducted at the present time.

This case study focused on a DSP - USAID initiative supporting private sector involvement in the supply chain. One of the key players was Zero Star Pessoal, a private business dealing with buying and selling of vegetables in Timor Leste. Interviews were conducted with the Zero Star manager and employees to gain in-depth information of its activities. To assess the impact of the initiative, focus group discussions were held with three farmer groups in Aileu, Maubisse and Hatubuilico to determine how the initiative benefited them. Semi-structured guide questions were used for the interviews of supply chain participants. Information from these interviews, together with secondary data were then used to develop the case study.

\section{THE DEZENVOLVE SETOR PRIVADO}

As part of development efforts in East Timor (officially known as Timor Leste) after independence, various international aid agencies, development agencies and foreign governments assisted the country to rebuild its economy. USAID focussed on private sector development. In 2006, Development Alternatives with funding from USAID initiated the Dezenvolve Setor Privado (DSP)or Private Sector Development Program. The focus of DSP is to target the private sector, and the approach was to work with farmers and traders to facilitate market linkages between producers and consumers.

One of the first small businesses DSP partnered with was Zero Star Uni Pessoal. Through targeted business assistance, DSP helped Zero Star improve its processes to increase its capacity to meet market demand and to move to the next level, targeting high end markets in Dili. 


\section{ZERO STAR UNI PESSOAL: BACKGROUND AND HISTORY}

Zero Star Uni Pessoal was founded by Komar Mendonca as a small business supplying wholesale vegetable products to the main wet markets in Dili. The business started when Mendonca moved to Dili to study in 1997. To support his tertiary education, Mendonca started to trade in Dili market, selling vegetables. After learning more about the trade, he decided to start his own business in buying and selling horticulture products. In 2006, Mendonca officially registered his business under the name Zero Star Uni Pessoal.

At that time, most of the products Mendonca bought from farmers were sold at the local market. He was unable to enter the more lucrative higher end supermarkets which mostly sold imported vegetables. In 2006, Zero Star got involved with DSP-USAID. Through its targeted business assistance and Small Grants Progam (SGP), the DSP-USAID project helped Mendonca transition to a professional wholesale business with cold chain management capacity, production planning with growers to produce new products and market to high-end buyers. Also, as part of DSP's assistance, Mendonca undertook training in horticultural production, post-harvest handling, packaging and grading and standardisation.

Zero Star first started delivering graded produce to Dili supermarkets in early 2007. By January 2008, Zero Star had a fully operational cold chain in place, with a cold truck used in the procurement of vegetables from the mountains and delivering produce to Dili. It also built a small cold storage facility in Dili where grading, sorting and packing were done.

There are 24 types of vegetables supplied by Zero Star to the high end markets in Dili. These includie tomatoes, carrots, cabbage, snap beans, snow peas, beans, lettuce, pumpkins, broccoli, kale, cauliflower, chinese cabbage, herbs, mango, and pineapple. These products are supplied through a network of over 100 independent growers in Hatubuilico, Maubisse, Aileu, Ermera and Liquica. These are largely small-scale farmers who depend on these markets for income and other essential needs. Buying arrangements with growers vary from scheduled planting for specialized products to cash on delivery purchases when products are available.

Services provided by Zero Star to farmers include access to inputs such as seeds, fertilizer, chemicals; training on production techniques and buying farmers produce. Farmers are provided the inputs, with special arrangements made for the repayment of these inputs. For example, farmers pay back the costs of seeds, fertilizers and chemicals after harvesting their crops. However, farmers who receive these inputs are obliged to sell their products to Zero Star. This is because aside from the inputs farmers receive, Zero Star also provides regular assistance to them in the production process and in harvesting. Capacity building included training in technical and agronomic aspects, integrated pest management, composting, harvest and post harvest operations, book keeping, grading and packing. Zero Star, with DSP's assistance also helped small scale farmers form a group.

\section{Distribution System}

In terms of the distribution system, Zero Star purchased the products through individual and group farmers in Hatubuilico, Maubisse, Aileu, Ermera and Liquica and transported them to Dili. Zero Star then cleaned, graded and packaged the vegetables before storing them in the cool room and finally distributing them to the clients (see Figure 2). The main buyers of these products are supermarkets (Kmanek, Landmark and Leader), restaurants, home delivery (mostly expatriate) and the local market. Zero Star distributes the products to the buyers once a week. Between July 2007 and July 2008, Zero Star supplied fresh produce to Dili supermarkets totalling $24960 \mathrm{~kg}$ with a retail sales value of US\$17,946 (DAI 2008). 
To compete with products from abroad, improving the 'quality' of the local product is very important. Zero Star's experience was that when they first contacted institutional buyers such as supermarkets and restaurants, most of the buyers did not believe and trust the local Timorese to deliver good quality products and deliver on time. To guarantee the buyers, they signed a Memorandum of Understanding (MOU) between Zero Star and the institutional buyers. This is hard and challenging for Zero Star at that time, but because of hard work and the support provided by DSP-USAID, Zero Star was able to deliver good quality products at the required time. Now, most of the buyers trust Zero Star and the demand for the product has increased. Buyers now have a choice on whether they will still rely on imported vegetables which are more expensive and requires a long bureaucratic process to import into the country, or they can purchase the products domestically at a lower price at the same time meets the quality standard.

In addition, coordination and communication between all parties involved in the supply chain needs to be well managed to increase the production and improve the quality of the product. Regular assistance needs to be provided to the farmers as most of the farmers in the production areas are illiterate. Training and assistance to the farmers are critical in improving their skills and knowledge in production and marketing of horticultural products.

Services provided by Zero Star such as training, regular assistance and others also created mutual trust between Zero Star and farmers which has led to better relationships. For example, by providing such services farmers felt that Zero Star was really helping them in terms of marketing their produce. On the other hand Zero Star also trusted that farmers will produce the product needed, with good quality and therefore meet the requirements of the market.

\section{How Effective was the Program?}

To measure whether the program of linking farmers to markets is successful, certain criteria were used including whether the involvement of farmers in the program increased farmers' income, whether the risk they faced was reduced, the impact on the business itself, Zero Star, and employment generated. These criteria are based on literature review of studies examining program effectiveness, comparison with program objectives and criteria identified in focus group discussions with farmers. Qualitative assessments were mainly used in this case study.

One of the main effects of the program is to improve the skills of participant farmers which translated to increased production. Moreover, the intervention of Zero Star, assisted by DSP-USAID, helped farmers link to major markets. This initiative was beneficial to farmers because the assistance and support provided to them reduced some of the problems they faced and assured them of a market for their produce. As a result, the volume of production and the quality of their products increased thus leading to an increase in income, lowered market risk and improved the consistency of the delivery of products to buyers. Over 100 outgrower farmers benefitted from the program.

For Zero Star Uni Pessoal, as a small private business, the rewards have been enormous. As mentioned previously, they were able to improve the quantity and quality of vegetables traded which has resulted in higher sales volume and income for Zero Star. The business that previously only targeted wet market in Dili has now become the first East Timorese wholesaler which has a fully operational cold chain. The employment effect was also significant. From a one-man operation, Zero Star now employs 12 permanent staff.

Hence, linking farmers to markets through Zero Star helped not only Zero Star but also small-scale farmers in terms of improving input availability, technical assistance and training, and marketing their produce. On one hand, this improved farmers' income and 
hence reduced poverty and on the other hand it increased production, quality and availability of the products, also benefiting consumers.

\section{Challenges Faced by Zero Star Uni Pessoal}

Despite the successful intervention of Zero Star in linking farmer to markets, there are some challenges it faces including the high volume of importation of horticulture products from Australia, Indonesia and Singapore. This is a real challenge for Zero Star because the quality of imported products is good and the parties involved in the business are big companies with huge capital. In addition, limited access to seeds and technologies for year round production is another challenges faced by Zero Star. As a small private business trying to meet the market demand for high quality products year round, the lack of seed varieties and technologies reduces Zero Star's capacity to compete with other companies. For example, the seeds of capsicum and broccoli need to be imported. Obtaining seeds overseas requires significant time and effort which is a stumbling block for the business in expanding its year round operations.

A further challenge is the bureaucratic procedure which contributes to the delay in bringing in inputs into East Timor. The delay in obtaining production inputs affects the production and marketing plans and hinders the farmers' and Zero Star's ability to respond to market demand. So far, there is no party involved in propagating new vegetable seed varieties and producing inputs such as fertiliser and pesticides in East Timor. These inputs have to be sourced outside East Timor.

The low skill levels of human resources is also challenging for Zero Star. As domestic demand for horticulture products increases, there is a need to increase the production and productivity of horticulture crops. However, the low skill level of most of the farmers in rural areas affects the ability to increase production to supply the market. Investment in human capital is needed to improve the skills of farmers.

Another challenge is the lack of support programs in the marketing of horticulture products. Most government programmes concentrate on the production side, mostly of grains and cereals. There is little attention paid to the marketing side for horticultural products. Meanwhile this sector has a huge potential for income generation, job creation and poverty alleviation.

Despite these challenges, Zero Star is continuing to develop its business in terms of improving the quality and quantity of the product and timely delivery so that it can compete with products from abroad.

\section{Critical Success Factors}

What are the factors that led to the success of Zero Star? The critical success factors presented below are based on discussions with the Zero Star manager and employees and on discussions with farmers groups. No attempt for prioritisation was made; but rather, a discussion of the critical success factors stakeholders considered important to the success of the business and the program. The critical success factors are as follows:

Targeting. Firstly, Zero Star only concentrated in horticulture products and limited its area coverage to Aileu, Maubisse, Hatubuilico, Ermera and Liquica. By targeting areas which are known as suitable areas for horticulture crops, Zero Star was able to reduce its operational risk. This is important particularly in the early stages of its business, as it was able to specialise in the production and handling of horticultural products, optimising the use of its resources, which may have been difficult if it diversified too early in the business. 
External support. Zero Star is fully supported by DSP-USAID in terms of providing facilities, grants (through the SGP), and training in production and post-harvest techniques, management, book keeping, etc. The external support provided the impetus to Zero Star to improve its processes and capacity to provide the market with what it demands. Without the external support, it would have taken Zero Star longer to move to the next level of its operation and enter high-end markets.

Infrastructure improvement. The construction of a cold storage facility in Dili and the availability of a cold truck is another critical success factor as it facilitated Zero Star's procurement operations. It allowed Zero Star to value add, sorting, repacking and storing prior to delivery to the clients. These facilities have enabled larger volumes of produce to be procured without significant wastage risks.

Innovativeness. Another success factor is Zero Star's innovativeness and responsiveness to customer needs. After identifying a niche for home deliveries, Zero Star introduced a \$10 produce box targeted at individual households. This new marketing strategy formed the basis of expansion for the business, extending its market reach to new customers. This particular market innovation focused on regular deliveries to individuals through common delivery points (e.g. offices) and restaurants.

Supporting farmers. One of the critical success factors in this initiative is the support provided to farmers to increase their production through training and the provision of critical farm inputs. Linking farmers to markets through Zero Star offered certain advantages such as improving the availability of inputs, technical assistance, transport and a market for their produce. In addition to removing some of the production constraints, Zero Star provided (sold) basic commodities such as rice, oil, etc. to farmers in remote areas which other traders or businesses cannot reach due to poor road conditions. These goods are provided to farmers by Zero Star in advance, with the cost of the goods deducted when farmers are paid for their crops during harvest time. Because of this, farmers trusted Zero Star in terms of buying and selling their produce and also in improving their access to basic necessities.

Developing trust. Trust is another important factor in the success of this initiative. When both sides (farmers and the trader) trust each other, operations run more smoothly and mutually beneficial longer term relations are developed. For example, in this particular case, during harvest time, Zero Star employees collect the products from farmers without cash payments. They just record the quantity collected from each farmer and deliver the vegetables to Dili. After a week, Zero Star pays the farmers according to the quantity supplied and the agreed price. This will not happen if there is no trust between both sides involved. The continuity of the product in the market is important. If there is trust between parties involved in the program, and everyone is benefitting, it is likely that they will be able to supply the vegetables year round.

\section{PROBLEMS AND CONSTRAINTS IN LINKING FARMERS TO MARKET}

Despite the successful intervention of Zero Star in linking farmers to markets, there are number of problems and constraints they face such as poor infrastructure, human resource constraints (lack of skills), lack of communication and lack of information facilities.

Bad road conditions, for example, in the production areas of Aileu, Maubisse and Hatubuilico affect the timely delivery and distribution of the product to the market. It also has a deleterious impact on the quality of the product and is one of the main reasons for the high percentage losses. This reduces the revenue of farmers and also of Zero Star. 
In addition, the lack of skilled human resources is a major problem across the country including the study area. While there are a lot of workers available in East Timor, most are unskilled. Hence, there is a need to invest more on training to improve the skills of workers. More capital investment in the area of human resources and capacity building is needed. As mentioned by the Zero Star manager, besides capital, there is a need to invest more time and effort in assisting farmers to increase the production and the quality of the product (Joanito, pers comm. 2009). This is because most of the farmers in the study area have little or no schooling at all. Apart from this, there is also a lack of communication and information technologies/ facilities; hence it is very difficult to get information on inputs and prices of outputs for agricultural production. So far, there are no institutions involved in providing information to farmers. Farmers do not know what the prices are for their products, what products are demanded by the markets, what are the prices for fertilizers and pesticides, etc. This disadvantages farmers in rural areas in terms of having a weak bargaining position when dealing with traders and collectors.

Furthermore, poor rural infrastructure, lack of extension service and poor communication facilities affect farmers' ability to better link with the market. The high transport cost brought about by these failures reduces the terms of trade of farmers.

\section{CONCLUSION AND LESSONS LEARNED}

Linking farmers to markets via the private sector involvement seems to be an effective model for improving farmers' income. Participating in the initiative reduced the risks faced by farmers in terms of having a clear market for their produce. This model removes the burden on individual farmers of finding the market for their product themselves, which is quite useful in an economy where infrastructure is lacking and farmers have limited ability to reach markets directly. Under this model, farmers can concentrate on increasing production and maintaining the quality and quantity demanded by the buyers.

As a newly independent country with a high rate of poverty and unemployment, the private sector such as Zero Star can play an important role in terms of helping small scale farmers in the production and marketing of their produce. The model of linking farmers to markets by strengthening the supply chain linkages, as demonstrated in Zero Star's case shows that production and quality of horticultural products can be increased. With support from international agencies, Zero Star was able to develop its business, provide employment opportunities and increase farmers' income in the region. This is an important contribution to the development of East Timor, particularly in rural areas which have limited access to infrastructure, communication and other services.

There are some important lessons that need to be learned from Zero Star's experience in linking farmers to markets. These are the need for regular assistance to farmers to improve their skills and facilitate access to inputs, attention to quality and timely delivery of the product, and good coordination and communication between all parties involved.

The challenge ahead is how to maintain the production and quality of the product so that it can continue to compete with imported products and expand its market. So what is needed?

First, more investment in rural infrastructure particularly roads, bridges and telecommunication systems is needed to lower transaction costs of farmers and make them more competitive. Improving rural infrastructure can facilitate farmers in selling their products to the market. Second, access to better information on prices and markets are also needed so that farmers can understand what is demanded by the market so they can produce according to market demand. Third, introduce new production technologies that will increase production and productivity such as new seeds, tunnels, greenhouses, etc. These technologies can solve the problem of seasonality, and will allow farmers to produce year round. Fourth, 
improve access of farmers to inputs by easing the barriers to importing fertilisers, pesticides and other farm inputs. Lastly, there is a need for government support in marketing agricultural products, particularly in accessing new markets including export markets as a long term strategy to develop the horticulture sector. Government support should not just concentrate on the production side but also support farmers in linking their products to the market. It is clear that linking farmers to markets can contribute to increasing farmers' income, increasing production and improving the quality of products. This will lead to a more job creation in rural areas and hence poverty reduction.

\section{Literature cited}

Alfaro, J.A. and Rabade, L.A. 2009. 'Traceability as a strategic tool to improve inventory management: a case study in the food industry', International Journal of Production Economics 118: 104-110.

Bernard, T. and Spielman, D.J. 2009. 'Reaching the rural poor through rural producer organizations? A study of agricultural marketing cooperatives in Ethiopia', Food Policy 34: 60-69.

DAI, 2008. Dezenvolve Setor Privadu, Annual Report July 2007 - July 2008, USAID, Dili.

De-Janvry, A., Fafchamps, M. and Sadoulet, E. 1991. 'Peasant behaviour with missing markets: some paradoxes explained', Economic Journal 101: 1400-1417.

Goetz, S.J. 1992. 'A selectivity model of household food marketing behaviour in SubSaharan Africa’, American Journal of Agriculture Economics 74: 444-452.

Hagan, F.E. 2002, Research Methods in Criminal Justice and Criminology, Allyn and Bacon, Boston.

IFAD, 2003. Rural market access for the rural poor in order to achieve the Millennium

Development Goals, Discussion paper, International Fund for Agricultural

Development.

Jayne, T., Zulu, B. And Nijhoff, J. 2006.'Stabilizing food markets in Eastern and Southern Africa', Food Policy 31(4).

Key, N., Sadoulet, E. and De-Janvry, A. 2000. 'Transaction costs and agricultural household supply response', American Journal of Agriculture Economics 82: 1273-1279.

Shepherd, A.W. 2007. Approaches to linking producers to markets, Occasional Paper No. 13, Agricultural Management, Marketing and Finance, Food and Agricultural Organization of the United Nations, Rome.

Shepherd, A.W. 2006. Strengthening market linkages to farmers through NGOs: Lessons from experiences to date, FAO, Rome. FAO/VECO workshop on enhancing capacities of NGOs and farmer groups to link farmers to markets, Bali, Indonesia, May 9-12.

Timmer, C.O. 1997. 'Farmers and markets: the political economy of new paradigms', American Journal of Agriculture Economics 79: 621-627.

Westgren, R. and Zering, K. 1998. 'Case study research methods for firm and market research, Agribusiness 14: 415-424.

Yin, R.K. 1994. Case Study Research: Design and Methods, 2nd edition, Sage, Beverly Hills, California. 


\section{Figures}

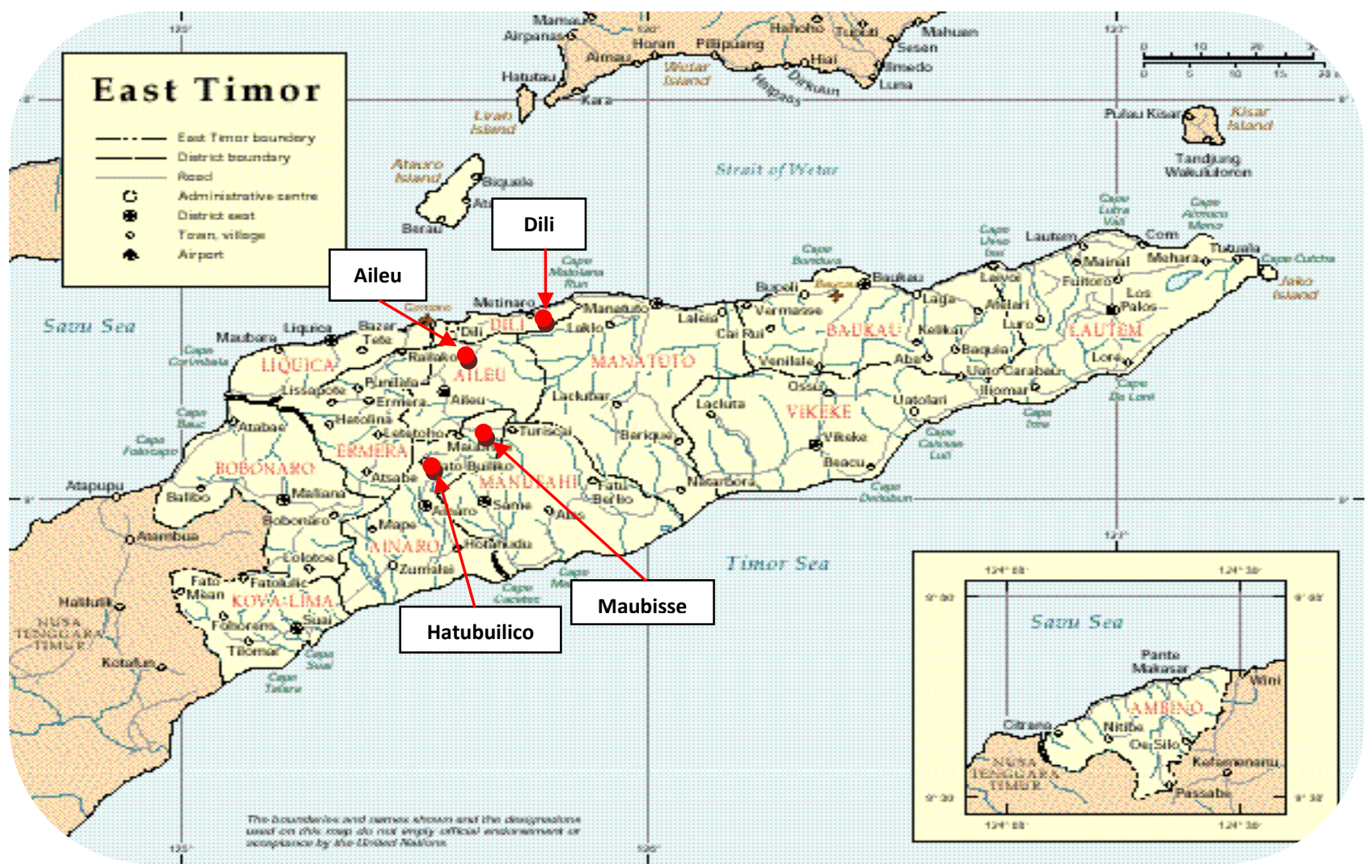

Figure 1. Map of the study sites

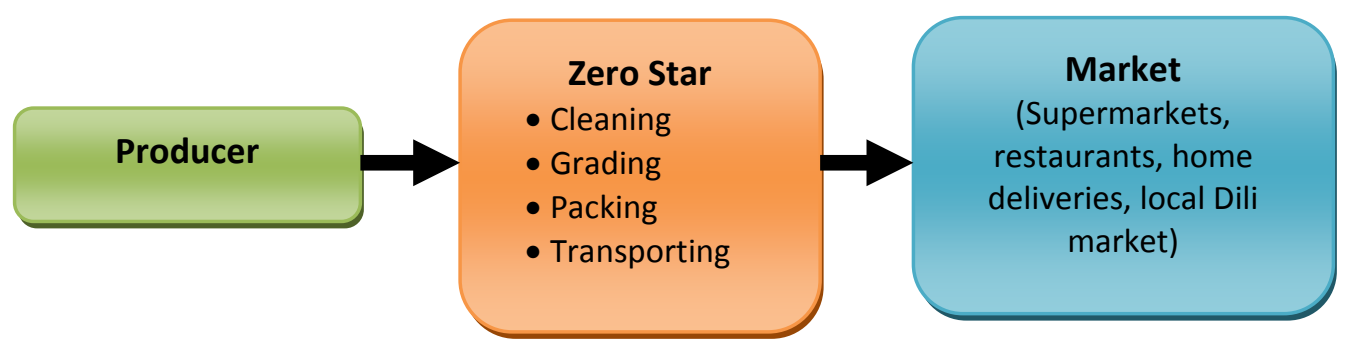

Figure 2. Distribution system of DSP-USAID supply chain participants 